\title{
Analysis of confined masonry with Strut and Tie models
}

\author{
Eukasz Drobiec ${ }^{1, *}$ Wojciech Mazur ${ }^{1}$ and Tomasz Rybarczyk ${ }^{2}$ \\ ${ }^{1}$ Silesian University of Technology, Department of Building Structures, 44-100 Gliwice, Poland \\ ${ }^{2}$ Solbet Spółka z o.o., 86-050 Solec Kujawski, Poland
}

\begin{abstract}
Strut \& Tie (S-T) models are used quite commonly for the analysis of reinforced concrete structures and in the calculation of masonry structures. Creating the S-T model of the confined masonry is slightly different from models of reinforced concrete or models of classic masonry structures. These models should take into account different stiffness of concrete and masonry. This article proposes a Strut \& Tie model for the analysis of confined masonry. The results of calculations were compared with the results of tests of full scale masonry walls with and without opening. Good compliance of the calculation results of S-T models with the test results was obtained.
\end{abstract}

\section{Introduction}

Strut \& Tie (S-T) models are commonly used for the analysis of confined walls subject to seismic results [1-6]. Such models can be, however, used to analyse monotonically loaded walls [7]. Requirements for preparing rod models are presented in the works [8-10]. The areas B and D are separated from the structures. The area B is the area to which the Bernoulli principle applies (plane sections remain plane after loading), and the stress change is linear. Local concentrations and/or disorders in geometry resulting in the curvilinear course of stresses were observed in the area D. Strut \& Tie models are prepared by replacing compression and tensile face of the structure with struts and ties. Assuming changes of these elements is relatively easy for areas B, but not so evident in the case of areas D. FEM models or the so-called path analysis for forces which require good understanding of stress distribution in the analysed area, can be used to support these assumptions.

This paper presents the concept of building Strut \& Tie models for confined masonry made of autoclaved aerated concrete. Calculations were performed for natural-scale research models of walls in compression. The analysis of cracks in research models and results of calculations for numerical models were used to assume the geometry of $\mathrm{S}$-T models used for calculations. The obtained values of load capacity were compared with results from testing confined solid walls in compression, walls with an opening and additional confining cores at the opening.

\footnotetext{
* Corresponding author: lukasz.drobiec@polsl.pl
} 


\section{Concept of building the S-T model of the confined masonry}

Preparing the strut-and-tie model of the confined masonry is different from preparing such models for reinforced concrete or traditional masonry structures. The analysis should include different stiffness of concrete and the wall. Therefore, reinforced concrete spandrel beams and confining cores were replaced with rebars. They formed a frame into which jointly supported rebars representing changes in stress in the masonry were placed. The tensile strength of the masonry was negligibly low, thus ties cannot be prepared from that material.

The following premises have to be met while preparing the rod model:

- the model should be as simple as possible - i.e. the number of rods in compression and tension should be reduced to minimum,

- At first, the rod system is built to represent the confinement, and then jointly supported rebars representing changes in stress in the masonry are placed,

- Reinforced concrete elements are assumed to take compressive and tensile stress, and elements representing the masonry only take the compressive stress,

- Calculations should include different stiffness of concrete and the confining structure,

- The arrangement of compressive elements representing walls should be agreed on the basis of the path analysis for forces or using calculations for models based on the FEM method.

The determined section width of the rod representing the masonry should include the real geometric parameters. If no information on cracks or stress distribution in the analysed wall is available, then the value not exceeding $d / 4$ should be assumed according to the paper [4], where $d$ is the length of the rod.

Figs. 1 and 2 based on [2] illustrate strut and tie models for selected confined walls in compression (fig. 1) and compression and shear (fig. 2). Reinforced concrete frames in the models are shown in a dark colour, and thicker rods in light grey colour represent the compressed wall. For shear walls with openings described in the paper [2], the analysis of results from numerical calculations was used to assume the wall movement could be modelled along the diagonal when the ratio of masonry height $h_{\mathrm{m}}$ to length $l_{\mathrm{m}}$ was within the range of $0.3<h_{\mathrm{m}} / l_{\mathrm{m}}<2.0$. For walls failing to meet the above criterion (too narrow walls), the structural movement was assumed only towards horizontal loading.

a)

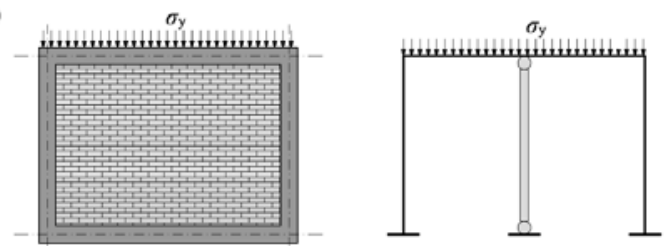

b)

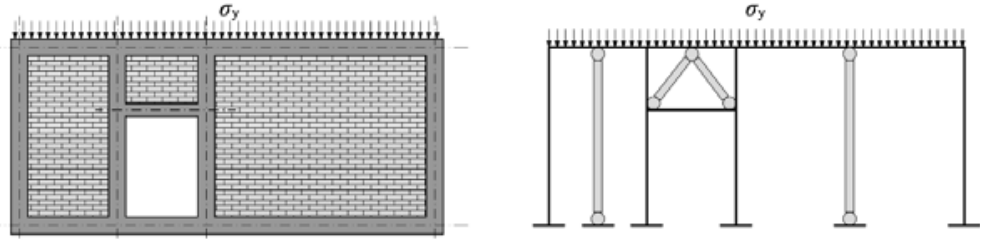

Fig. 1. Research models of confined walls in compression and corresponding strut and tie models: a) a wall without an opening, b) a wall with an opening [2] 
a)
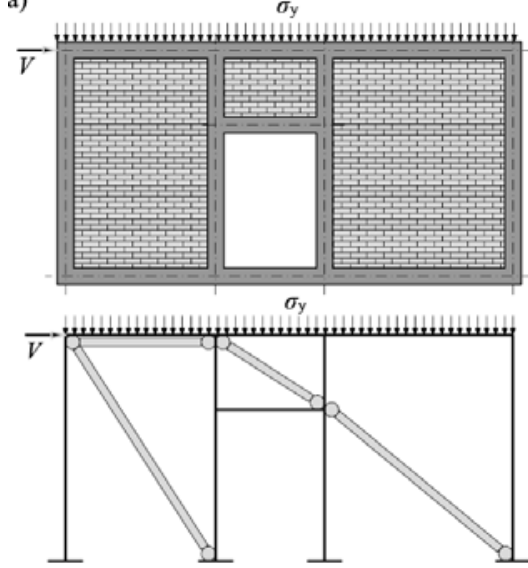

c)

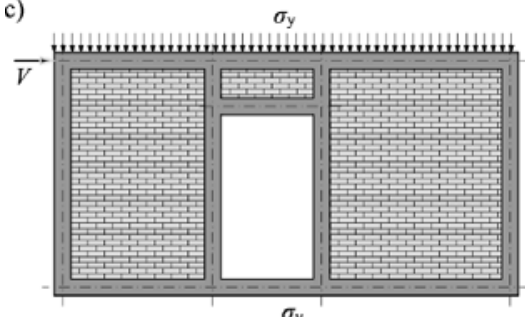

T. - b)

$\sigma_{\mathrm{y}}$
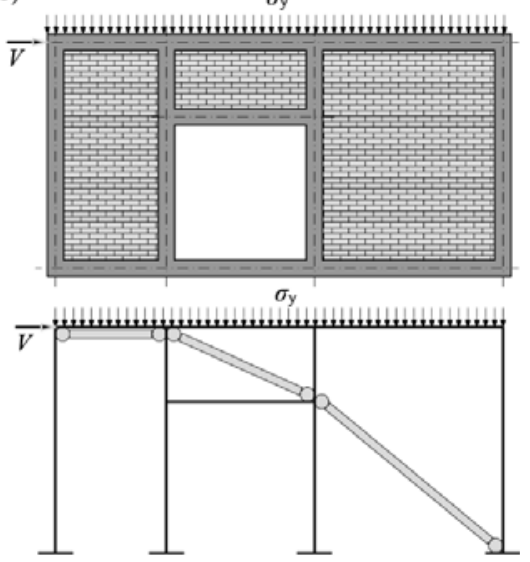

d)
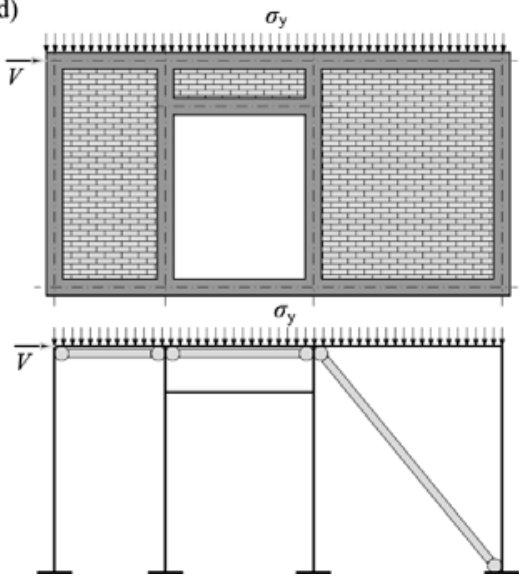

Fig. 2. Research models of confined walls in compression and corresponding strut and tie model: a) all strips in the masonry meet the condition $0.3<h_{\mathrm{m}} / l_{\mathrm{m}}<2.0$, b) for the left strip $\left.h_{\mathrm{m}} / l_{\mathrm{m}}>2.0, \mathrm{c}\right)$ for the mid strip $h_{\mathrm{m}} / l_{\mathrm{m}}<0.3$, d) for the left strip $h_{\mathrm{m}} / l_{\mathrm{m}}>2.0$ and the mid strip $h_{\mathrm{m}} / l_{\mathrm{m}}<0.3[2]$

\section{Description of analysed models}

Research models were built from blocks of autoclaved aerated concrete with the thickness of $180 \mathrm{~mm}$, laid in the thin-layer mortar. The normalised compressive strength of masonry units was $f_{\mathrm{b}}=4.0 \mathrm{~N} / \mathrm{mm}^{2}$, and mortar mean compressive strength was $f_{\mathrm{m}}=6.1$ $\mathrm{N} / \mathrm{mm}^{2}$. Compressive strength of the masonry was $f_{\text {test }}=2.97 \mathrm{~N} / \mathrm{mm}^{2}$ in walls with unfilled vertical joints and $f_{\text {test }, 2}=2.61 \mathrm{~N} / \mathrm{mm}^{2}$ in walls with filled vertical joints. Modulus of elasticity was $\mathrm{E}=2040 \mathrm{~N} / \mathrm{mm}^{2}$ and $\mathrm{E}=2447 \mathrm{~N} / \mathrm{mm}^{2}$, respectively and Poisson's ratio equal to $v=0.18$ was the same for walls with filled and unfilled joints. Models were built from the concrete of class $\mathrm{C} 20 / 25$ and steel with the yield strength of $500 \mathrm{~N} / \mathrm{mm}^{2}$. The method of basic material tests and detailed results were described in the papers [11-13].

Tests were scheduled and conducted on 12 confined walls. They included four walls confined along their perimeter and without openings, four walls confined along their perimeter and with openings, and four walls confined along their perimeter and with additional cores at an opening. Each series of tests was conducted on one wall with filled 
and one wall with unfilled vertical joints. Joints were filled by applying mortar on the lateral areas of the face of masonry units, excluding a tongue.

Models were $4.43 \mathrm{~m}$ long and $2.49 \mathrm{~m}$ high. All models were built on precast reinforced concrete ground beam with openings to put through starter bars of cores. Vertical bars and the top spandrel beam were monolithic units prepared at four stages. At first, spandrel beams were concreted up to the half of the wall height or the lintel level (inner spandrel beams). Typical precast AAC lintels reinforced with three rebars having a diameter of 8 $\mathrm{mm}$ and open stirrups were used in masonry. Walls with additional internal cores required destruction of support zones (Fig. 3) to use lintels to anchor their reinforcement properly in the vertical core. The reinforcement of confining elements in all models is illustrated in Fig. 4.

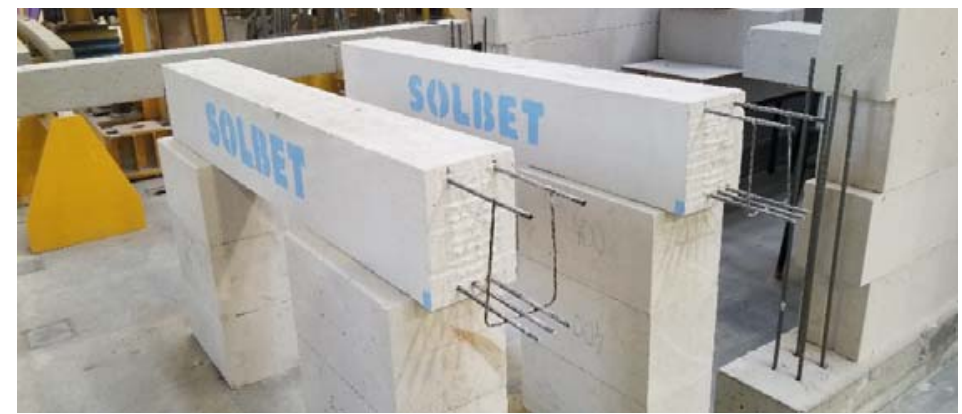

Fig. 3. Lintels with removed concrete from the support zone intended to be used in models with additional confinement around the opening

Confined walls with unfilled vertical joints were designated as MS-Z1, and similar walls but with filled vertical joints were designated as MS-Z2. Walls with peripheral confinement and an opening were labelled as MSO-Z1 and MSO-Z2, and walls with two additional inner confinements at the opening were labelled as M2SO -Z1 and M2SO-Z2.

Research models were loaded with two hydraulic actuators with the operational range of $1000 \mathrm{kN}$, fastened to two steel frames of the strong floor in the Laboratory of the Civil Engineering Faculty, Silesian University of Technology. The actuators were placed symmetrically at the spacing span of $2.25 \mathrm{~m}$ (Figs. 5 and 6). The load imposed by the actuators was distributed by two concentrated forces by means of steel crossbeams. Models were additionally loaded with a tendon system by means of piston actuators fixed to the bottom of the strong floor. The operating range of these actuators was $25 \mathrm{kN}$, thus the load of $50 \mathrm{kN}$ slightly increased by the weight of the steel crossbeam was exerted on one pair of tendons. The model at the level of the top spandrel beam (tie beam) was loaded with four forces from crossbeams loaded with the actuators fixed to frames and with three tendon systems loaded by means of piston actuators fixed to the bottom of the strong floor. Piston actuators transferred the load to steel tendons, and then through crossbeams, to the model.

Tests did not demonstrate any significant effect of joint filling on the load capacity of confined masonry. Thus, results for models with unfilled vertical joints were analysed. Walls MS-Z1 without openings were destroyed at the total force of $1663.4 \mathrm{kN}$ as the compressive strength of the wall was exceeded. Confined walls MSO-Z1 with an opening were destroyed at the total force of $499.8 \mathrm{kN}$ as the compressive strength of the wall at the lintel support was exceeded. Destructive force for models with additional inner cores was greater, and equalled $580.6 \mathrm{kN}$, and the failure of models was caused by lintel shear. 
a)

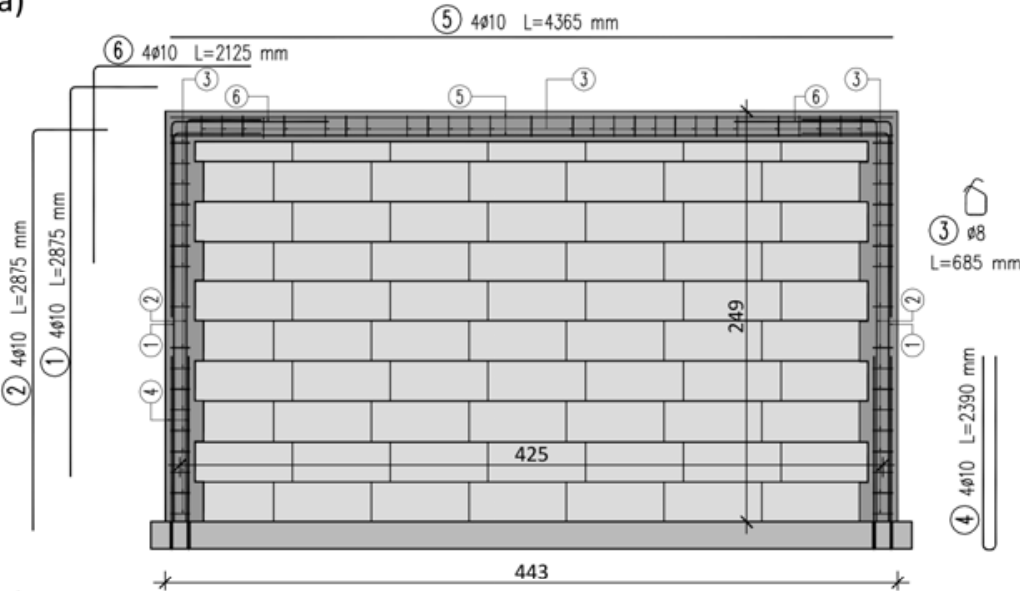

b)
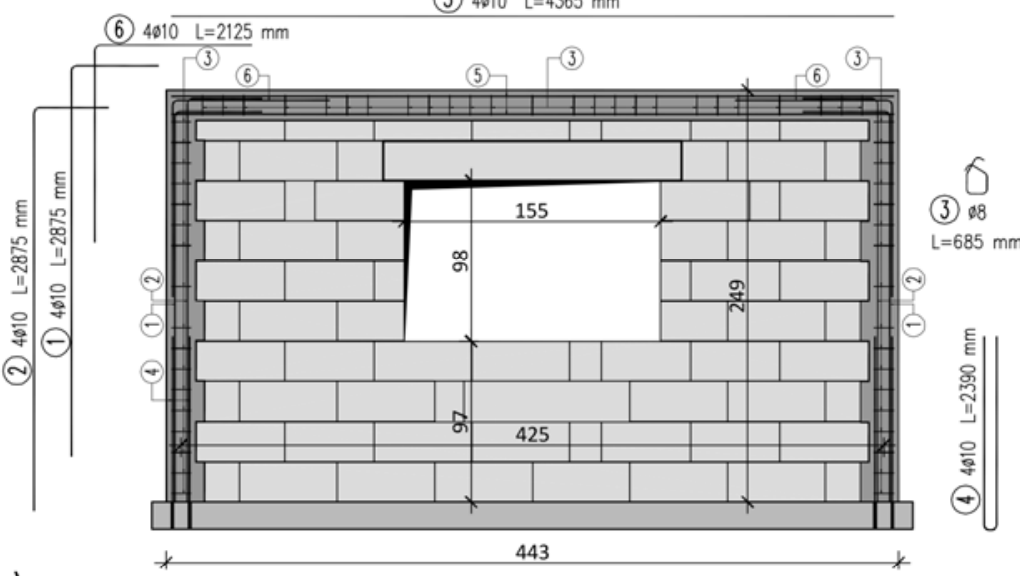

c)

(5) $4810 \quad L=4365 \mathrm{~mm}$

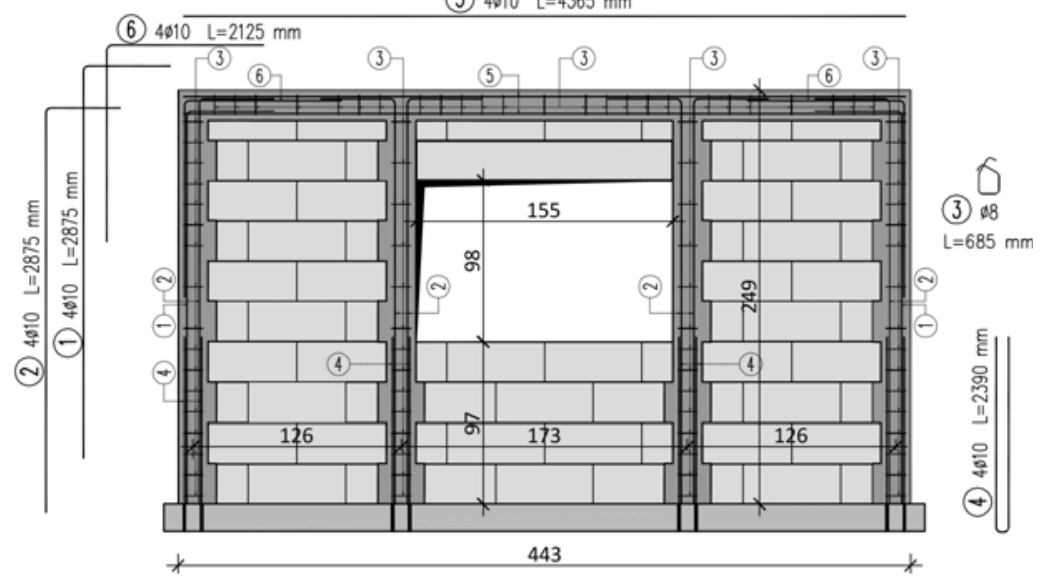

Fig. 4. Research models: a) confined model without an opening, b) model with peripheral confinement, c) model with peripheral confinement and additional cores at the opening 


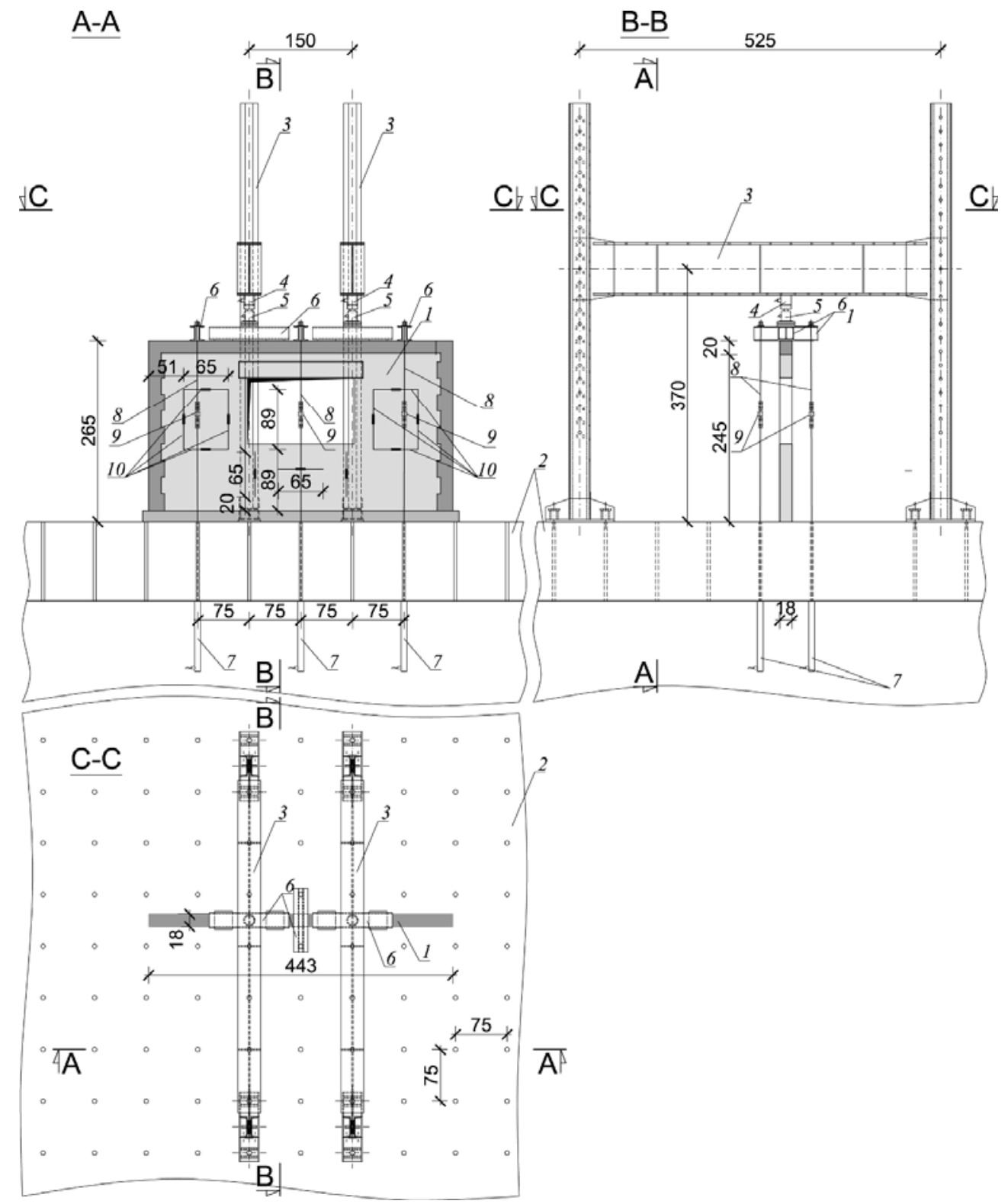

Fig. 5. A test stand: 1 - research model, $2-$ strong floor 3 - steel frame, 4 - actuator, 5 cylindrical dynamometer, $6-$ cross beam, 7 - piston actuator, 8 - tendon, $9-$ dynamometer, $10-$ measuring base for displacements.

The method of conducting tests and detailed results were described in the papers $[14,15]$. They also present the method of destroying the tested wall models. 
a)

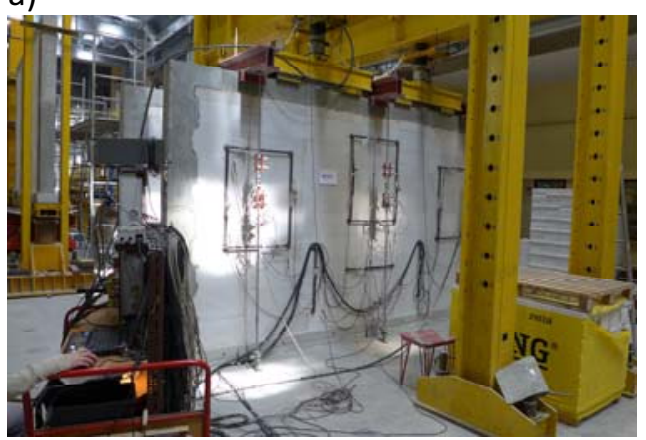

b)

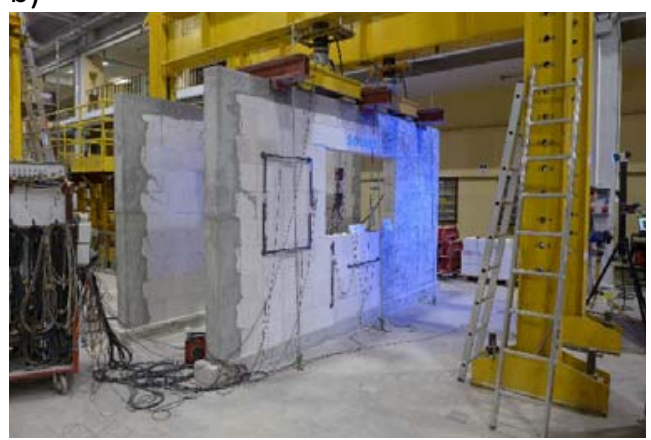

c)

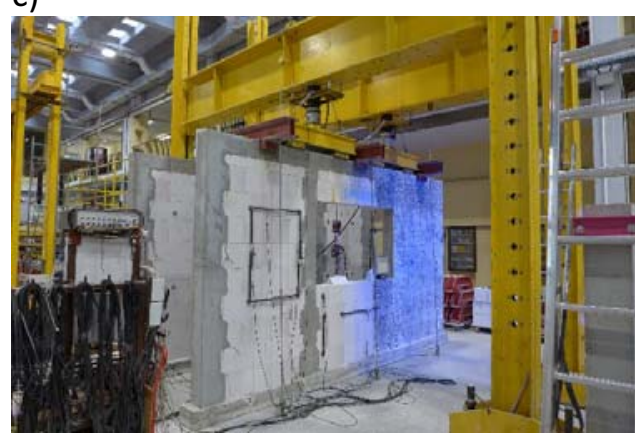

Fig. 6. Models before tests: a) MS-Z1 confined models without an opening, b) MSO-Z1 models with peripheral confinement, c) M2SO-Z1 models with peripheral and internal confinement

\section{Numerical analysis and assumed geometry of S-T model}

Calculations based on the finite element method were performed to adopt the structure of compressed rods in S-T models representing masonry. One half of the wall model was built using the symmetry of research models. An elastic-plastic model on Menétrey-Willam surface was used to describe the material behaviour under compression [16]. The used boundary surface was appropriate for adjusting the shape at deviatoric section to tests performed on particular materials. Behaviour of the material under tension was described using Rankine criterion, the model of smeared cracks developing in uniform directions, and the exponential function of fatigue. ATENA 2D software was used for computations. Contact elements were applied at the interface between masonry units. Parameters of the material and contact elements were determined on the basis of our own material tests performed under uniaxial, biaxial, and triaxial stress states. Those tests were thoroughly presented in the papers [17-20]. Described numerical models had been partially published in the papers [21 and 22].

Cracks in models and the distribution of stress in numerical models were analysed. Those analyses offered the basis for the assumption of the geometry of rod models for the S-T method. Figure 7 presents cracks, stresses and deformations observed in the numerical model and the proposed rod model. 
a)
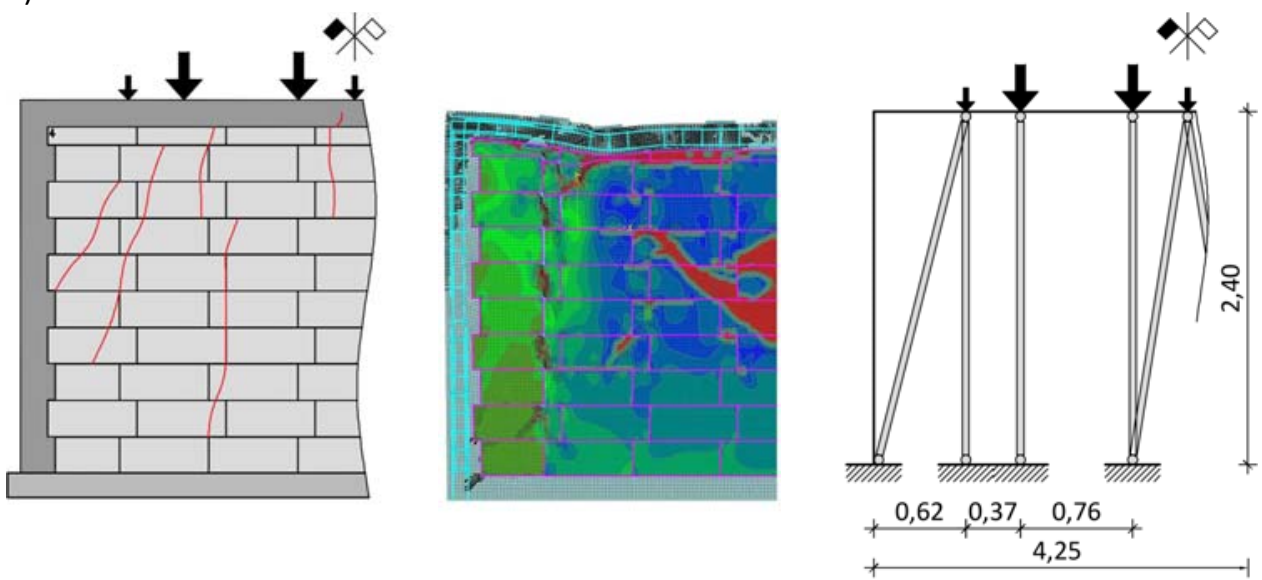

b)
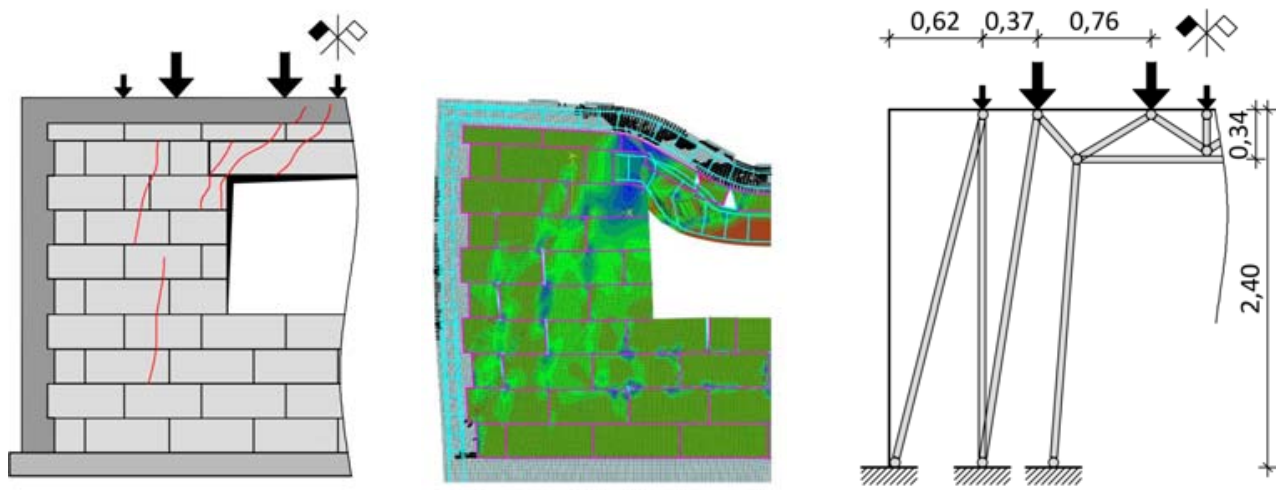

$$
\begin{array}{r}
0,62,0,48 \text { 4, } \\
+\quad 4,25
\end{array}
$$

c)
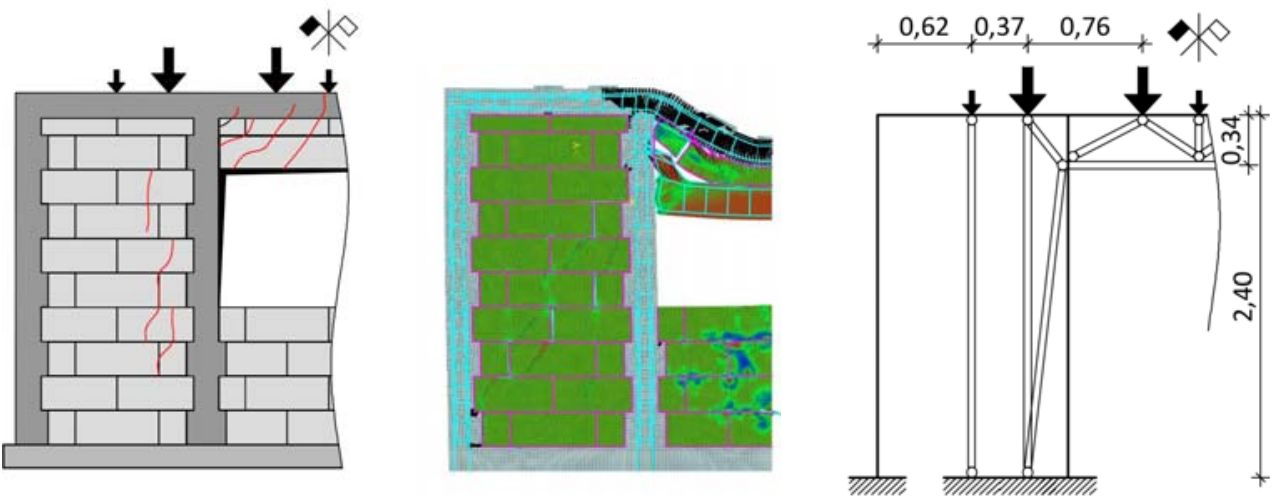

; 0,63,0,36,0,27.

Fig. 7. Arrangement of cracks, main stress in FEM and recommended rod model for: a) MS-Z1 confined models without an opening, b) MSO-Z1 models with peripheral confinement, c) M2SO-Z1 models with peripheral and internal confinement 


\section{Results of calculations using S-T models}

Strut-and-tie models were prepared according to schemes illustrated in Fig. 7. $\mathrm{S}$-T models included real values of material parameters and real geometrical values.

Research models were loaded in two stages. At first, three forces of $50 \mathrm{kN}$ were applied to the model by tendons, and then models were loaded until their destruction using two actuators fixed to frames (forces generated by the actuators were distributed through cross beams). Therefore, forces of $50 \mathrm{kN}$, the self-weight of walls and steel fixtures were exerted on rod models, and values of four other forces representing loads from frames were differentiated until internal forces corresponding to the limit criterion were achieved. Compressive strength of masonry, and additionally the load capacity of models with an opening, were assumed as the limit criterion. According to tests performed as a part of the doctoral thesis [23], the load capacity of the system lintel-masonry-spandrel beam (tie beam) was much greater than the load capacity of the lintel itself. The papers [ [21 23] presented results from testing the system of lintel-masonry-spandrel beam with various numbers of masonry layers over the lintel. Models for those tests were built from the same materials (mortar, masonry units, lintels, concrete, reinforcement) as models in the analysed tests. The papers [21, 23] determined, inter alia, the load capacity of the lintel-one layer of masonry-tie beam system with reference to bending $(17.6 \mathrm{kNm})$ and shear $(39.3 \mathrm{kN})$. Those values were regarded as the limit criterion for the $\mathrm{S}-\mathrm{T}$ method.

Table 1 presents the comparison of test results and calculations using the S-T method. The total force recorded during tests and the total force exerted on the computational model were compared. Like in the tests, the limit criterion assumed for S-T models was achieved as the compressive strength in the wall (the model without any opening), compressive strength at the lintel support (models with peripheral confinement and an opening), and the load capacity of the load at the lintel (the model with peripheral and internal confinement and an opening) were exceeded.

Table 1. Comparison of test results and S-T method results

\begin{tabular}{|c|c|c|c|}
\hline Analysed wall & $\begin{array}{c}\text { Total loading of S-T } \\
\text { model } \\
\mathbf{P S}_{\mathbf{S}-\mathbf{T}} \mathbf{k N}\end{array}$ & $\begin{array}{c}\text { Total loading during } \\
\mathbf{t e s t s} \\
\mathbf{P}_{\text {Test }} \mathbf{k N}\end{array}$ & $\mathbf{P}_{\text {S-T }} / \mathbf{P}_{\text {Test }}$ \\
\hline $\begin{array}{c}\text { MS } \\
\text { Confined walls without an } \\
\text { opening }\end{array}$ & 1370.0 & 1663.4 & 0.824 \\
\hline $\begin{array}{c}\text { MSO } \\
\text { Walls with peripheral } \\
\text { confinement and openings }\end{array}$ & 442.0 & 499.8 & 0.884 \\
\hline $\begin{array}{c}\text { M2SO } \\
\text { Walls with peripheral } \\
\text { confinement and openings }\end{array}$ & 534.0 & 580.5 & 0.920 \\
\hline
\end{tabular}

Results from the tests and S-T method were compatible. Depending on the analysed model, computed loading contributed to $82 \div 92 \%$ of values obtained from tests. The highest level of compliance was observed for the model with additional inner cores.

\section{Conclusions}

Binding standards do not contain recommendations on determining the load capacity of confined masonry. Computational analyses conducted on Strut \& Tie models demonstrated that such models can be successfully used for computational analyses of confined masonry. The compliance of S-T method results with test results was acceptable. 


\section{References}

1. S. Brzev, J.J. Perez-Gavilán, Proc.of the $16^{\text {th }}$ Intern. Brick and Block Masonry Conf., Padova, Italy, (2016).

2. K.V. Ghaisas, D. Basu, S. Brzev, J.J. Perez-Gavilán, Constr. Build. Mater. 147, 677700 (2017).

3. L.Liberatore, F. Noto, F. Mollaioli, P. Franchin, Eng. Struct. 167, 533-548, (2018).

4. M.J.N. Priestley, M.Calvi, Earthq Spectra, No. 7, 3, 413-37 (1991),

5. P.P. Sreejith, P.P. Sivan, A. Praveen, C. Gajendran, V. Nisha, Procedia Techn. 24, 155160 (2016).

6. D. Tripathy, V. Singhal, Eng. Struct. 188, 290-304 (2019).

7. R. Jasiński, IOP Conf. Ser.: Mater Sci. Eng. 245, (2017).

8. J. Wranik, Calculation of reinforced concrete structures using rod models. (Publisher of School of Engineers, Opole 1993). In Polish.

9. W. Starosolski, Reinforced concrete structures according to Eurocode 2 and related standards. T III. (PWN Scientific Publishing House, Warsaw 2012). In Polish.

10. L. Buda-Ozóg, Reliability of reinforced concrete structures designed by the strut and tie method. Rzeszów University of Technology Publishing House, 2019. In polish.

11. Ł. Drobiec, R. Jasiński Cem. Wapno Beton 5, 383-399 (2019).

12. Ł. Drobiec, Mauerwerk, Heft 5, 21, 332-342, (2017).

13. Ł. Drobiec, Mauerwerk, Heft 6, 23, 387-403, (2019).

14. Ł. Drobiec, T. Rybarczyk , Ce/Papers 4, 2, 409-415, (2018).

15. Ł. Drobiec Inżynieria i Budownictwo 5, 240-245, (2019). In Polish.

16. P. Menétrey,K.J. Willam, ACI Struct. J. 92, 3, 311-318 (1995).

17. R. Jasiński, IOP Conf. Ser.: Mater. Sci. Eng. 245, (2017).

18. Ł. Drobiec, R. Jasiński, Procedia Eng. 193, 470- 477, (2017).

19. Ł. Drobiec, Procedia Eng. 193, $462-469$ (2017).

20. Ł. Drobiec, Mauerwerk, Heft 1, 24, (2020).

21. Ł. Drobiec,, R. Jasiński, W. Mazur, Cem. Wapno Beton 5, 339-413, (2017).

22. W. Mazur, T. Rybarczyk, R. Jasiński., Ł. Drobiec, Acta Scientiarum Polonorum, Architectura, 4, 17, 93-104, (2018).

23. W. Mazur, Analysis of the bearing capacity and deformability of selected system lintels made of autoclaved aerated concrete, $\mathrm{PhD}$ Thesis, Silesian University of Technology Publisher, Gliwice, Poland (2018). In Polish. 